\title{
Skin tissue fluid levels of cefotiam in healthy man following oral cefotiam hexetil
}

\author{
H. C. Korting ${ }^{1}$, M. Schäfer-Korting ${ }^{2}$, F. Kees ${ }^{3}$, A. Lukacs ${ }^{1}$, and H. Grobecker ${ }^{3}$ \\ ${ }^{1}$ Dermatologische Klinik und Poliklinik der Universität, München \\ ${ }^{2}$ Pharmakologisches Institut für Naturwissenschaftler der Universität, Frankfurt/Main and \\ ${ }^{3}$ Pharmakologisches Institut der Universität, Regensburg, FRG
}

Received: July 31, 1989/Accepted in revised form: January 19, 1990

Summary. Cefotiam hexetil is a pro-drug of cefotiam available for oral administration. To evaluate cefotiam concentrations at the active site in skin and soft-tissue infections, drug levels in skin suction blister fluid (SBF), cantharides blister fluid (CBF) and serum were determined. Six healthy subjects received oral cefotiam $400 \mathrm{mg}$ as cefotiam hexetil. On an other day $200 \mathrm{mg}$ was injected intravenously.

Following the oral dose, the bioavailability of cefotiam was $45.5 \%$, and the maximum concentration in serum of $2.6 \mathrm{mg} \cdot 1^{-1}$ was obtained at $2.1 \mathrm{~h}$. Peak concentrations in both types of blister fluid $\left(0.9 \mathrm{mg} \cdot \mathrm{I}^{-1}\right)$ were significantly lower than after the iv dose (SBF $1.4 \mathrm{mg} \cdot \mathrm{l}^{-1}$, CBF $\left.1.5 \mathrm{mg} \cdot 1^{-1}\right)$, and the peak levels occurred later (3.3 versus $1.5 \mathrm{~h}$ in $\mathrm{CBF}$ ). Despite the delay, the extent of penetration was about $100 \%$ following either mode of administration (SBF, iv dose $112 \%$, oral dose $117 \%$ ). The cefotiam level in skin blister fluids declined significantly more slowly than the serum level. Following the oral dose, the mean terminal half life was serum $0.8 \mathrm{~h}, \mathrm{SBF} 2.6 \mathrm{~h}$ and $\mathrm{CBF}$ $4.6 \mathrm{~h}$.

Cefotiam concentrations in the blister fluids were close to the $\mathrm{MIC}_{90}$ of Staphylococcus aureus, S. epidermis and $H$. influenzae and exceeded the $\mathrm{MIC}_{90}$ of Streptococci, E. coli and Proteus mirabilis.

Thus, the oral administration of cefotiam $400 \mathrm{mg}$ t. i.d. should be curative in the majority of bacterial infections of the skin and soft-tissues.

Key words: Cefotiam, skin tissue fluid; pharmacokinetics, concentration in the skin

Second generation cephalosporins, such as cefotiam, are highly active against common gram-negative aerobic organisms [1]. And, in contrast to many third generation cephalosporins, cefotiam also inhibits gram-positive cocci [2]. The broad spectrum of second generation cephalosporins makes them candidates for the treatment of skin and soft-tissue infections in which mixed bacterial colonization may occur [3]. Moreover, the severity of such diseases may require instantaneous treatment before the microorganism has been cultured.

The need for repeated parenteral administration has restricted the use of new cephalosporins in out-patients [4], so cephalosporin esters suitable for oral administration (such as cefotiam hexetil or cefuroxime axetil) [5-7] have been developed. During absorption, the ester is hydrolysed and the active agent is released [5, 8]. In a first clinical study, cefotiam hexetil 300-600 mg/day was effective in $87 \%$ patients suffering from bacterial infection of the skin (Kumazawa J, 1987 unpublished data). Cure rates exceeding $90 \%$ were reported with cefuroxime axetil [6] and cefaclor $[6,9,10] 0.5-2.0 \mathrm{~g} /$ day.

To study cefotiam concentrations at the site of bacterial infections in skin and soft-tissue infections following cefotiam hexetil (SCE2174), skin blister fluid [11,12] and serum levels have been determined in healthy volunteers. The drug levels following a single oral dose have been compared to those after an intravenous injection.

\section{Material and methods}

\section{Subjects}

Six healthy subjects ( 5 male, 1 female, aged $23-35$ y, weight $60-$ $90 \mathrm{~kg}$, height $173-200 \mathrm{~cm}$ ) participated in the experiments after giving written informed consent to it. The subjects refrained from taking other drugs, alcohol and caffeine.

\section{Protocol}

The study followed a randomized, cross-over design. During the preceding night of cefotiam and cefotiam hexetil administration food intake was not allowed. The subjects received one oral dose of $400 \mathrm{mg}$ cefotiam as cefotiam hexetil (2 tablets of $200 \mathrm{mg}$ ) and one iv injection $(200 \mathrm{mg})$ of cefotiam dihydrochloride (Spizef ${ }^{-}$; injection period $3 \mathrm{~min}$; end of infusion was taken as 0 time point). Both preparations were supplied by Takeda Pharma, Stolberg, FRG. The drugs were administered together with breakfast. The washout period between the administrations was 7 days. Blood samples to provide serum were taken before drug administration, and after 5, 10, 20,30, and $45 \mathrm{~min}$ as well as $1,1.5,2,2.5,3,4,5,6$, and $8 \mathrm{~h}$. Suction blister 


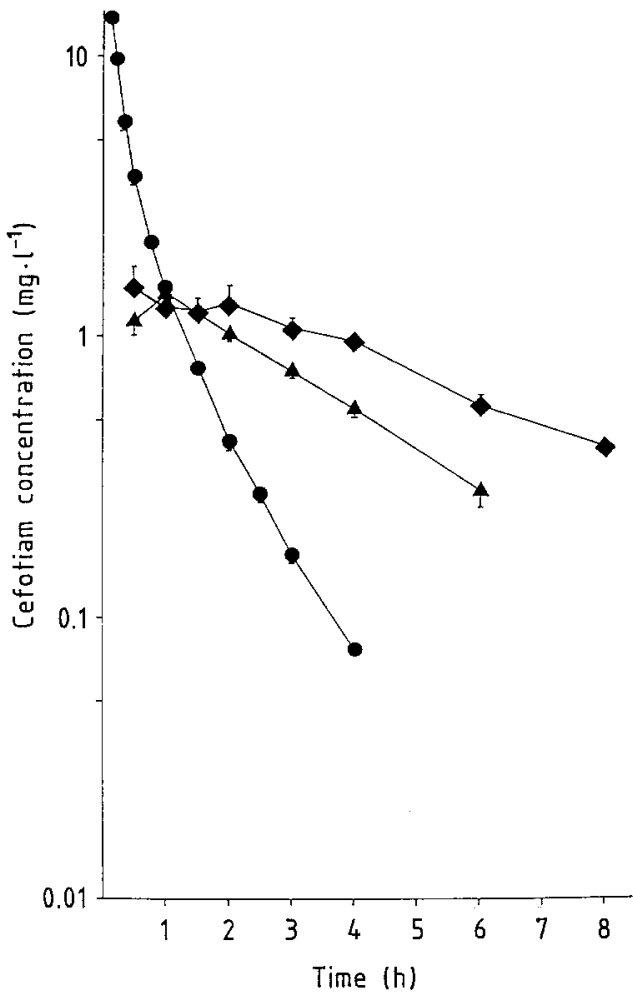

Fig. 1. Cefotiam concentrations in serum $(\bullet), \operatorname{SBF}(\boldsymbol{\Delta})$ and $C B F$ ( ) following a single intravenous dose of $200 \mathrm{mg}$ cefotiam in six healthy volunteers. Mean (SEM)

fluid (SBF) and cantharides blister fluid (CBF) were obtained at 0.5 , $1,2,3,4$, and $6 \mathrm{~h}$, and $\mathrm{CBF}$ at 1.5 and $8 \mathrm{~h}$, too. The induction of cantharides and suction blisters started 13 and $3 \mathrm{~h}$ before dosing. Details of the blistering procedures are given elsewhere $[13,14]$. Serum and blister fluid samples were stored at $-20^{\circ} \mathrm{C}$ until analyzed.

\section{Drug assay}

Cefotiam was determined in serum, SBF and CBF by HPLC(F. Kees et al., in preparation). In brief, serum and blister fluids were deproteinized with acetonitrile, which was removed by extraction with dichloromethane. $50 \mu \mathrm{l}$ of the aqueous phase (kept frozen until injected) were directly chromatographed using reversed-phase HPLC. The eluate was monitored at $254 \mathrm{~nm}$. Linear results were obtained in the range cefotiam 0.1 to $10 \mu \mathrm{g} / \mathrm{ml}$; the relative standard deviation was 3 to $7 \%$. The method also allowed determination of the isomeric $\mathrm{d} 3$-cefotiam (detection limit $0.01-0.02 \mathrm{mg} / \mathrm{l}$ ).

Serum standards for the calibration graphs were prepared using blank human serum. Blister fluid standards were made in phosphate buffer $\mathrm{pH}$ 7.0.

\section{Protein binding}

Cefotiam binding in SBF and CBF was calculated as described by McNamara et al. [15], based upon serum binding of $40 \%$ [16] and the albumin concentration in serum and skin blister fluids previously determined [13].

\section{Pharmacokinetic calculations}

Maximum cefotiam concentrations $\left(\mathrm{C}_{\max }\right)$ in serum, $\mathrm{SBF}$ and $\mathrm{CBF}$, and the times to those maximum concentrations $\left(t_{\max }\right)$, were obtained from the measured data. The elimination rate constant $(\mathrm{k})$ was calculated from the terminal loglinear decline in concentration in the appropriate fluids. The areas under the cefotiam concentration-time curves (AUC), serum clearance (Cl), the volume of distribution $\left(\mathrm{V}_{z}\right)$ and bioavailability of cefotiam following cefotiam hexetil were calculated.

Drug penetration into the skin blister fluids (Pen) was obtained as the area ratio blister fluid/serum based upon free drug levels.

\section{Statistical evaluation}

The data are expressed as the arithmetic mean (SEM). They were evaluated statistically using the Wilcoxon test for tied pairs. $P \leq 0.05$ was considered as significant.

\section{Results}

\section{Intravenous dose}

Mean serum and blister fluid concentrations of cefotiam are depicted in Fig. 1. The maximum concentration in serum was $16.2 \mathrm{mg} \cdot \mathrm{I}^{-1}$ and the cefotiam level had declined to $0.078(0.004) \mathrm{mg} \cdot \mathrm{1}^{-1}$ at $4 \mathrm{~h}$. The mean terminal half life of the serum level was $0.8 \mathrm{~h}$ (Table 1 ). Plasma clearance amounted to $31.8(1.8) \mathrm{l} \cdot \mathrm{h}^{-1}$ and the volume of distribution was $0.35(0.002) 1 \cdot \mathrm{kg}^{-1}$.

The maximum concentrations of $1.4 \mathrm{mg} \cdot 1^{-1}$ in SBF and $1.5 \mathrm{mg} \cdot \mathrm{l}^{-1}$ in CBF were obtained after 1.0 and $1.5 \mathrm{~h}$, respectively. Thereafter, the blister fluid levels exceeded the serum concentration. The mean concentration in the blister fluids declined to SBF 0.28 (0.03) and CBF 0.56 $(0.03) \mathrm{mg} \cdot \mathrm{l}^{-1}$ at $6 \mathrm{~h}$ and the mean terminal half lives were $2.3 \mathrm{~h}$ in SBF and $3.5 \mathrm{~h}$ in $\mathrm{CBF}$, thus significantly exceeding the serum half life. The fraction unbound of cefotiam was 0.775 in SBF and 0.635 in CBF. Thus, cefotiam penetration into SBF and CBF amounted to 112 and $151 \%$, respectively.

The serum concentration of $\mathrm{d} 3$-cefotiam was below the detection limit in four subjects and was up to $0.061 \mathrm{mg} \cdot 1^{-1}$ in the others. In all volunteers, $\mathrm{d} 3$-cefotiam in CBF was always below the detection limit. In SBF minor concentrations of the metabolite were found in four volunteers $\left(\leq 0.045 \mathrm{mg} \cdot \mathrm{l}^{-1}\right)$.

\section{Oral dose}

The mean cefotiam levels are shown in Fig. 2. The peak serum level of $2.6 \mathrm{mg} \cdot 1^{-1}$ occurred after $2.1 \mathrm{~h}$. At 4 and $6 \mathrm{~h}$ cefotiam concentrations were $0.59(0.15)$ and $0.11(0.03)$ $\mathrm{mg} \cdot 1^{-1}$, respectively.

The bioavailability of cefotiam following oral ingestion of cefotiam hexetil was $45 \%$. The terminal half life was $0.8 \mathrm{~h}$ (Table 1). In SBF the mean peak concentration of $0.9 \mathrm{mg} \cdot \mathrm{l}^{-1}$ was obtained at $3.5 \mathrm{~h}$, and the corresponding values in $\mathrm{CBF}$ were $0.9 \mathrm{mg} \cdot \mathrm{1}^{-1}$ and $3.3 \mathrm{~h}$. The maximum concentrations in the blister fluids were significantly lower and the time to the peak concentrations were significantly prolonged as compared to the iv dose. At $6 \mathrm{~h}$ the cefotiam concentration in SBF was $0.47(0.05) \mathrm{mg} \cdot 1^{-1}$, thus significantly exceeding the drug level following the iv dose. CBF concentrations were $0.52(0.05)$ and 0.30 $(0.06) \mathrm{mg} \cdot \mathrm{l}^{-1}$ at 6 and $8 \mathrm{~h}$. The terminal half lives in SBF 
Table 1. Pharmacokinetics of cefotiam following single oral and iv doses of 400 and $200 \mathrm{mg}$; respectively $(n=6 ; \bar{x}(\mathrm{SEM}))$

\begin{tabular}{|c|c|c|c|c|c|c|}
\hline \multirow[t]{2}{*}{ Parameter } & \multicolumn{2}{|l|}{ Serum } & \multicolumn{2}{|l|}{ SBF } & \multicolumn{2}{|l|}{$\mathrm{CBF}$} \\
\hline & iv & oral & iv & oral & iv & oral \\
\hline$t_{\max }[h]$ & $0.083^{\mathrm{a}}$ & $2.1(0.3)$ & 1.0 & $3.5(0.6)^{\mathrm{b}}$ & $1.5(0.2)$ & $3.3(0.3)^{b}$ \\
\hline $\mathrm{t}_{1 / 2}[\mathrm{~h}]$ & $0.8(0.06)$ & $0.8(0.08)$ & $2.3(0.3)^{c}$ & $2.6(0.5)^{c}$ & $3.5(0.4)^{\mathrm{c}}$ & $4.6(0.8)^{c}$ \\
\hline $\mathrm{AUC}\left[\mathrm{mg} \cdot 1^{-1} \mathrm{~h}\right]$ & $6.4(0.3)$ & $5.8(0.5)$ & $5.5(0.2)$ & $5.3(1.1)$ & $9.0(0.3)$ & $6.3(0.9)$ \\
\hline
\end{tabular}

a first sampling time 5 min after administration; ${ }^{b} P \leq 0.05$ versus iv administration; ${ }^{\mathrm{a}} P \leq 0.05$ versus serum

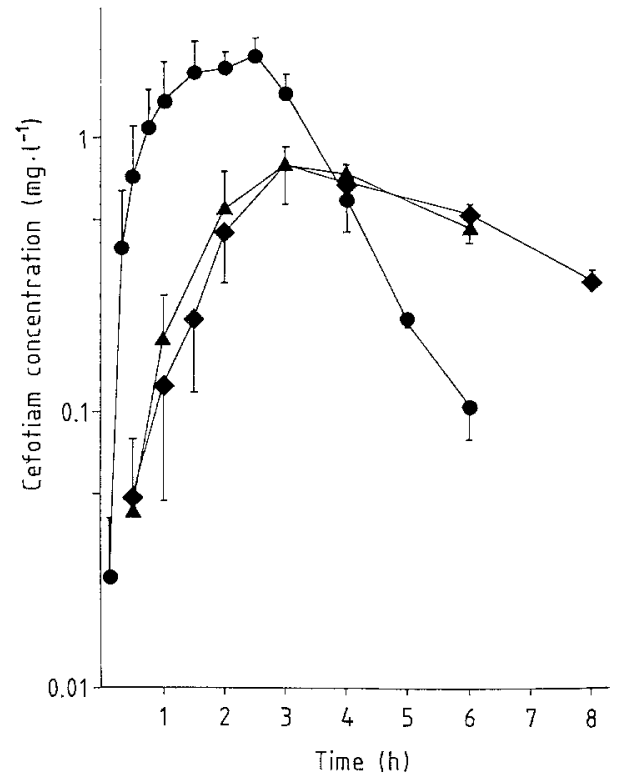

Fig. 2. Cefotiam concentrations in serum $(\bullet), \operatorname{SBF}(\boldsymbol{\Delta})$ and $\mathrm{CBF}$ $(\diamond)$. Six healthy volunteers received a single oral dose of $400 \mathrm{mg}$ cefotiam as cefotiam hexetil. Mean (SEM)

$(2.6 \mathrm{~h})$ and $\mathrm{CBF}(4.6 \mathrm{~h})$ was in accordance with the corresponding values following the intravenous injection. Cefotiam penetration into SBF and CBF was 117 and $114 \%$, respectively.

d3-Cefotiam was detected in serum samples from five subjects. The peak level $\left(0.019\right.$ to $\left.0.097 \mathrm{mg} \cdot \mathrm{I}^{-1}\right)$ was found after 1 to $1.5 \mathrm{~h}$. In four subjects $\mathrm{d} 3$-cefotiam was detectable in CBF ( 0.010 to $0.045 \mathrm{mg} \cdot \mathrm{l}^{-1}$ ), and in SBF the maximum d3-cefotiam level $\left(0.051\right.$ to $\left.0.099 \mathrm{mg} \cdot \mathrm{1}^{-1}\right)$ was observed 2 to $4 \mathrm{~h}$ after the dose of cefotiam. At $6 \mathrm{~h}$ the SBF level of d3-cefotiam was $0.045(0.023) \mathrm{mg} \cdot \mathrm{l}^{-1}$.

\section{Discussion}

In a previous study serum and skin blister fluid levels of cefotiam were evaluated following a single intramuscular dose of $1 \mathrm{~g}$. Drug penetration into the blister fluid was about $100 \%$. SBF and CBF levels were well above the MIC of Neisseria gonorrhoeae, suggesting the suitability of a $1 \mathrm{~g}$ single-dose regimen of cefotiam for gonorrhoea $[17,18]$, as subsequently proven in a clinical trial [19]. In the present study, the SBF and CBF levels of cefotiam were lower than following i. m. administration [17], even after correction for the dose administered.
Following the iv dose, cefotiam concentrations in serum and the derived pharmacokinetic parameters were in accordance with those reported by Brisson et al [20], if corrected for the $200 \mathrm{mg}$ dose.

The isomer $\mathrm{d} 3$-cefotiam was found in very low concentrations following the iv injection, but after cefotiam hexetil p.o. higher $\mathrm{d} 3$-cefotiam concentrations were observed in serum and blister fluids. This suggests isomerization of cefotiam during drug absorption. Isomerization has also been observed in homogenates of small intestine, liver and in plasma from mice [5]. d3-Cefotiam is devoid of antibacterial activity [21].

Following cefotiam hexetil, the bioavailability of cefotiam was $45 \%$, and its terminal half life was $0.8 \mathrm{~h}$. The concentrations of $\mathrm{d} 3$-cefotiam, cefotiam bioavailability and terminal half life are close to the data reported by Couet et al. [1987, unpublished data]. The bioavailability of cefotiam is close to that of cefuroxime administered as cefuroxime axetil $(52 \%)$ [22] but is less than that of cefaclor availability $(\geq 65 \%)[23]$

Levels in CBF have been evaluated following cefuroxime $1 \mathrm{~g} \mathrm{im}$. The terminal half life in CBF $(1.6 \mathrm{~h})$ was consistent with the serum half life, and the maximum level in $\mathrm{CBF}$ was $12.6 \mathrm{mg} / \mathrm{l}$ [12], which is close to the peak cefotiam level following $1 \mathrm{~g}$ im [17]. With cefotiam, however, the drug level in SBF and CBF declined more slowly than the serum concentration (Table 1). Such behaviour is frequently observed with drugs of high hydrophilicity and very rapid elimination [18]. Thus, cefotiam concentrations in both blister fluids exceeded the serum concentrations from about $4 \mathrm{~h}$ after the oral dose, and even 1 to $1.5 \mathrm{~h}$ after following the iv dose (Figs. 1,2). Therefore, active concentrations will persist in the skin and probably also in soft tissues for a longer period of time than in serum.

No essential difference between cefotiam concentrations in SBF and CBF were observed. Following an oral dose, the penetration of cefotiam into SBF and CBF amounted to $117 \%$ and $114 \%$, respectively, which means that tissue penetration was close to the $100 \%$ expected, if the free drug were homogeneously distributed between plasma and tissue fluid [18]. The inflammatory reaction of the tissues obtained by the induction of cantharides blisters, but not by suction blistering [13, 18], did not have a major influence on tissue penetration by cefotiam.

Cefotiam only binds to a minor extent to serum proteins (serum $40 \%$; SBF $22.5 \%$ ). Therefore, MIC values are virtually not affected by the addition of serum to the incubation medium [24], and drug levels in blister fluids may be compared to in vitro activity without the need to 
correct for protein binding. Following $400 \mathrm{mg}$ p.o. and $200 \mathrm{mg}$ i.v., the peak concentrations of cefotiam in the blister fluids were close to the $\mathrm{MIC}_{90}$ values of Staphylococcus aureus, S. epidermidis and H. influenzae [2, 25,26], and they exceeded the $\mathrm{MIC}_{90}$ values of Streptococcus pyogenes, S. pneumoniae, E. coli and Proteus mirabilis [2]. These organisms are frequently isolated from skin infections [3]. It appears that the doses used in the investigation of cefotiam hexetil in skin infections (100-200 mg t.i.d.) were low, and increasing the dose should result in a higher cure rate, as described for cefuroxime axetil and cefaclor $[6,9,10]$.

In conclusion, the present results suggest that cefotiam hexetil $400 \mathrm{mg}$ t.i.d. p.o. should be curative in the majority of skin and soft-tissue infections. Nevertheless, in severe cases, as well as in instances of treatment failure, increasing the daily dose would be advisable.

\section{References}

1. Grimm H (1981) Bakteriologische In-vitro-Untersuchungen mit einem neuen Cephalosporin: Cefotiam. Arzneimittelforsch 31: 1867-1869

2. Bodey GP, Fainstein V, Hinkle AM (1981) Comparative in vitro study of new cephalosporins. Antimicrob Agents Chemother 20: 226-230

3. Finch R (1988) Skin and soft-tissue infections. Lancet I: 164-167

4. Johnson JD (1986) The cephalosporins in dermatologic practice. Int J Dermatol 25: 427-430

5. Nishimura T, Yoshimura Y, Miyake A, Yamaoka M, Takanohashi K, Hamaguchi N, Hirai S, Yashiki T, Numata M (1987) Orally active 1-(cyclohexyloxycarbonyloxy)alkyl ester prodrugs of cefotiam. J Antibiot (Tokyo) 40: 81-90

6. Parish LC, Cocchetto DM, Werner K, Jungkind DL, Witkowski J (1987) Cefuroxime axetil in the treatment of cutaneous infections. Int J Dermatol 26: 389-393

7. Gudgeon AC, Vandenburg MJ, Wight LJ, Griffiths GK, Kelsey M (1987) Is oral cefuroxime axetil suitable for the treatment of unidentified bacterial infection of skin and soft tissue? Br J Clin Pract 41: 954-956

8. Harding SM, Williams PEO, Ayrton J (1984) Pharmacology of cefuroxime as its 1-acetoxyethyl ester in volunteers. Antimicrob Agents Chemother 25: 78-82

9. Finnerty EF, Folan DW jr (1979) Cefaclor in the management of common bacterial skin diseases. Cutis 24: 304-306

10. Dillon HC jr, Gray BM, Ware JC (1979) Clinical and laboratory studies with cefaclor: efficacy in skin and soft tissue infections. Postgrad Med J 55 [Suppl 4]: 77-81

11. Kiistala U (1968) Suction blister device for separation of viable epidermis from dermis. J Invest Dermatol 50: 129-137
12. Wise R, Gillett AP, Cadge B, Durham SR, Baker S (1980) The influence of protein binding upon tissue fluid levels of six $\beta$-lactam antibiotics. J Infect Dis 142: 77-82

13. Schäfer-Korting M, Korting HC, Mutschler E (1985) Human plasma and skin blister fluid levels of griseofulvin following a single oral dose. Eur J Clin Pharmacol 29: 109-113

14. Schäfer-Korting M, Korting HC, Mass L, Klesel N, Grigoleit HG, Mutschler E (1986) Cefodizime penetration into skin suction blister fluid following a single intravenous dose. Eur J Clin Pharmacol 30: 295-298

15. McNamara PJ, Gibaldi M, Stoeckel K (1983) Fraction unbound in interstitial fluid. J Pharm Sci 72: 834-836

16. Adam D (1982) Pharmakokinetik von Cefotiam. In: Lode H, Adam D: Cefotiam - Standortbestimmung eines neuen Antibiotikums. Excerpta Medica, Amsterdam, pp 63-72

17. Korting HC (1984) Plasma and skin blister fluid levels of cefotiam and cefmenoxime after single intramuscular application of $1 \mathrm{~g}$ in gonorrhea. Chemother 30:277-282

18. Schäfer-Korting M, Korting HC (1989) Skin blisters and skin windows: an access to total and free drug concentrations in the skin. In: Maibach HI, Lowe NJ (eds) Models in Dermatology, Vol 4. Karger, Basle, pp 45-62

19. Korting HC, Neubert U (1985) Treatment of gonorrhoea with cefotiam: activity in vitro and clinical results of a 1 -gram-singledose regimen. Dermatologica 171: 264-268

20. Brisson AM, Bryskier A, Millerioux L, Fourtillan JB (1984) Pharmacokinetics of cefotiam administered intravenously and intramuscularly to healthy adults. Antimicrob Agents Chemother 26:513-518

21. Murphy CF, Webber JA (1972) Alteration of the dihydrothiazine ring moiety. In: Flynn EH (ed) Cephalosporins and penicillins. Chemistry and biology. Academic Press, New York pp 134-182

22. Finn A, Straughn A, Meyer M, Chubb J (1987) Effect of dose and food on the bioavailability of cefuroxime axetil. Biopharm Drug Dispos 8: 519-526

23. Glynne A, Goulbourn RA, Ryden R (1978) A human pharmacology study of cefaclor. J Antimicrob Chemother 4: 343-348

24. Wise W, Andrews JM, Bedford KA (1981) Cefoperazone and cefotiam two new cephalosporins: an in vitro comparison. Antimicrob Agents Chemother 7:343-352

25. Braveny I, Machka K (1979) Activity of cefotiam (CGP 14 211/E) against Haemophilus influenzae, Neisseria gonorrhoeae, and Neisseria meningitidis, including $\beta$-lactamase-producing isolates, in vitro. Antimicrob Agents Chemother 1:225-227

26. Fock RRE, Thormählen B, Laufs R (1983) In vitro activity of 13 cephalosporin antibiotics against the most frequent species isolated from blood cultures. Drugs Exp Clin Res 9: 639-646

Priv.-Doz. Dr. H.C. Korting

Dermatologische Klinik und Poliklinik

der Ludwig-Maximilians-Universität

Frauenlobstraße 9-11

D-8000 München 2, FRG 